\title{
A INAPLICABILIDADE DO MARCO CIVIL DA INTERNET PELOS TRIBUNAIS FEDERAIS: ANÁLISE DE JULGADOS ENVOLVENDO TUTELA DO PRINCÍPIO DA PRIVACIDADE DOS USUÁRIOS DA REDE
}

\section{A LANDMARK CIVIL INAPPICABILITY INTERNET BY FEDERAL COURTS: REVIEW OF DEEMED INVOLVING THE PRINCIPLE OF PROTECTION NETWORK USERS OF PRIVACY}

\author{
Bruno Mello Corrêa de Barros \\ Clarissa Teresinha Lovatto Barros ${ }^{2}$
}

\begin{abstract}
RESUMO
O presente artigo buscou demonstrar a inaplicabilidade do arcabouço legal do Marco Civil da Internet (MCI) nas decisões dos Tribunais Federais do país no tocante às demandas, envolvendo a proteção do direito à privacidade dos usuários da rede. Apontou-se para a necessidade de interpretação ampla do direito à privacidade, evidenciando aspectos desse direito fundamental a partir de doutrinadores constitucionalistas. Adotou-se o entendimento de Pérez Luño de transposição da percepção que separa imagem, honra, intimidade e privacidade, tendo em vista a aceleração provocada pela inovação tecnológica e científica que permeia a sociedade informacional. Utilizou-se o método de abordagem dedutivo, efetuando revisão e análise bibliográfica com o intuito de refletir criticamente sobre o princípio da privacidade. Para tanto, empregou-se a ferramenta de pesquisa de jurisprudência nos sites dos Tribunais Regionais Federais, colocando a expressão Marco Civil da Internet. Constatou-se a reduzida utilização de parâmetros do MCI nas decisões dos Tribunais Federais, mas, de qualquer forma, não se pode desprezar o aspecto progressivo da legislação ao assegurar garantias para tutela do direito à privacidade na Internet.
\end{abstract}

Palavras-chave: Marco civil da internet, Direito à privacidade, Tribunais federais

\begin{abstract}
This paper aims to demonstrate the inapplicability of Cool Civil Marco Internet framework (MCI) decisions of the Federal Courts of the country in relation to the demands involving the protection of the right to privacy of network users. He pointed to the need for broad interpretation of the right to privacy, revealing aspects of this fundamental right from constitutional scholars. Adopted the understanding Pérez Luno transposing the perception that separates image, honor, intimacy and privacy, with a view to acceleration caused by scientific and technological innovation that permeates the informational society. We used the deductive method of approach, making literature review and analysis in order to critically reflect on the principle of privacy. Therefore, we used the case law research tool on the websites of the Federal Regional Courts, putting "Civil Marco Internet" expression. It was found to reduced use of MCI parameters in the decisions of federal courts, but in any case, one can not disregard the progressive aspect of the legislation to ensure guarantees for protection of the right to privacy on the Internet.
\end{abstract}

\footnotetext{
${ }^{1}$ Mestrando em Direito pela Universidade Federal de Santa Maria - UFSM, Rio Grande do Sul, (Brasil). E-mail: brunom_barros@hotmail.com

${ }^{2}$ Mestranda em Direito pela Universidade Federal de Santa Maria - UFSM, Rio Grande do Sul, (Brasil). E-mail: clovatto@yahoo.com.br
} 
Keywords: Civil marco internet, Federal courts, Right to privacy 


\section{INTRODUÇÃO}

O artigo buscou demonstrar a (in)aplicabilidade de parâmetros estabelecidos no Marco Civil da Internet (MCI) nas fundamentações das decisões proferidas pelos Tribunais Superiores do país, especialmente nas demandas envolvendo tutela do princípio da privacidade dos usuários da rede, tendo em vista a obrigatoriedade de os provedores guardarem os registros de conexão e de acesso. Para tanto, apontou-se para uma necessidade de interpretação ampla do direito à privacidade, mostrando como a doutrina nacional trata esse direito. Aliado a isso, evidenciou-se aspectos desse direito fundamental como maneira de colaborar para a efetividade da garantia ao direito da privacidade.

Na Sociedade Informacional, demonstrou-se uma série de efeitos produzidos pela Internet com os quais o poder Estatal, especialmente o Poder Judiciário, precisa lidar. Por vezes, a criação de instrumentos jurídicos adequados para tratar dessas novas realidades perdura ao longo dos anos tal como ocorreu com o Marco Regulatório Civil para a Internet, Lei Federal $\mathrm{n}^{\mathrm{o}} 12.965$ (BRASIL, 2014). Após três meses de debate público sobre a regulamentação, o governo federal está realizando a sistematização das opiniões enviadas pela plataforma online para, então, elaborar uma minuta do texto do decreto.

Na perspectiva deste artigo, o direito à privacidade representa uma garantia essencial ao desenvolvimento do indivíduo e ao exercício da liberdade de expressão. Adotou-se o entendimento de Pérez Luño (2005) de transposição da percepção que separa imagem, honra, intimidade e privacidade, tendo em vista a aceleração provocada pela inovação tecnológica e científica que permeia a contemporaneidade. Recorreu-se, ainda, ao entendimento de Rodotá (2008) de que há a necessidade de ampliar o conceito de privacidade para além da dimensão individualista. Realizou-se a composição de marco teórico, adotando-se, também os ensinamentos de Manuel Castells, que cunhou a expressão sociedade informacional, a qual se caracteriza pela inserção do informacional em diferentes searas da vida, determinando novos padrões de relacionamento social.

Utilizou-se o método de abordagem dedutivo, partindo de uma visão geral do tema e da realização da análise doutrinária para definir o conceito. Efetuou-se a revisão e a análise bibliográfica com o intuito de refletir criticamente sobre o princípio da privacidade. Para tanto, evidenciou-se o método de procedimento monográfico, investigando os tribunais 
a partir do emprego da expressão "Marco Civil da Internet" na ferramenta de pesquisa de jurisprudência nos sites dos Tribunais Regionais Federais.

O presente trabalho estruturou-se em duas partes. A primeira abordou o princípio da privacidade, a partir da construção teórica de doutrinadores constitucionalistas, bem como no arcabouço legal do Marco Civil Internet. A segunda parte versou a respeito da análise crítica das decisões dos Tribunais Superiores do país calcadas no Marco Civil da Internet, legislação construída de maneira colaborativa, tendo como plataforma de debate a internet.

\section{PRINCÍPIO DA PRIVACIDADE NA SEARA DO MARCO CIVIL DA INTERNET}

Há uma série de obras que mostram o amplo potencial transformador das relações humanas advindo das Tecnologias de Informação e Comunicação (TIC). Nesse sentido, Castells (2008) registra que no término dos anos 90, as iniciativas de monopólio da internet pelo governo dos Estados Unidos, país no local havia concentração maior de usuários da internet à época, ingressaram em esgotamento. A utilização militar da intercomunicação computacional deixou de ser o mais proeminente para o meio social e, nesse cenário, criaramse as grandes redes de iniciativa privada.

Desde então, as TIC foram gradativamente remodeladas pelos grupos de cidadãos, sobretudo universitários e empresas com fins comerciais. Esse redesenho possibilitou diferentes aplicações, afora aquelas de aspectos eminentemente militar, inicialmente tracejadas, chegando inclusive à esfera governamental. Ao se configurar como interconexão de várias redes de computadores, a internet possibilitou a troca de dados em diferentes formatos, afora elevar o acesso às informações. Percebe-se que surgiu, concomitantemente ao desenvolvimento tecnológico, uma nova economia classificada por Casttels (2008), de informacional e em rede, em que a produtividade e a competividade são dependentes da capacidade de produzir e aplicar informações. Além disso, essa sociedade é em rede porque as condições históricas e a concorrência se conectam diretamente.

Os Estados perceberam no ambiente virtual um instrumento portador de condições para modificar a estrutura estatal e detentor da possibilidade de ressignificar a participação da população face ao poder estatal. Inclusive, a pesquisa TIC Governo Eletrônico 2013, organizada pelo Núcleo de Informação e Coordenação do Ponto BR (NIC.br), identificou que 
90\% dos órgãos públicos federais e estaduais prestaram pelo menos um serviço público online, revelando uma nova demanda para o desenho de políticas de serviços públicos eletrônicos (PESQUISA...2014).

Nesse contexto da sociedade informacional, em que as TIC não representa unicamente uma ferramenta de comunicação e sim espaço para que os internautas sejam criadores de informação, pode-se afirmar que o Marco Civil foi produto da rede em razão de ter sido disponibilizado no campo virtual e construído com auxílio dos usuários ${ }^{3}$. Assim, oportuno assinalar o entendimento de Saldanha (2015, p. 159).

[...] No final da década de 90 do século passado, foi apresentado ao Congresso Nacional do Brasil projeto de lei com vista à criação de marco regulatório para a internet. Essa iniciativa derivou do reconhecimento da influência da internet no campo da política, seja para promover a democracia, seja para facilitar atitudes autoritárias. Por outro lado, decorreu da necessidade de regular, no plano interno, um dos efeitos da globalização, ou seja, a ultrapassagem das fronteiras por meio das relações virtuais deslocalizadas.

Evidencia-se, desse modo, o potencial transformador das relações jurídicas advindos das TIC na construção do próprio Marco Civil da Internet, na qual a sociedade informacional participou da feitura da legislação, bem como do debate público no ambiente virtual referente a pontos que carecem de regulamentação. Percebe-se, inclusive, que a Lei revela a influência do direito internacional dos direitos humanos sobre o direito interno. Nesse sentido, a organização ARTIGO $19^{4}$, ao analisar a compatibilidade do MCI no Brasil com as normas internacionais apontou que se trata de legislação progressiva, com garantias gerais satisfatórias para a proteção da liberdade de expressão e o direito à privacidade na Internet, pois garante esse direito considerado essencial para assegurar que os indivíduos tenham a confiança para se expressarem livremente na Internet. Assim, como bem assinala Saldanha (2015, p.161), “o Marco Civil da Internet visa atender a uma das exigências que a mundialização apresenta, ou seja, a necessidade de regulação das relações jurídicas que nascem das relações digitais".

\footnotetext{
${ }^{3}$ O Marco Civil começou a ser elaborado em 2009 pelo Ministério da Justiça, em parceria com o Centro de Tecnologia e Sociedade, da Fundação Getulio Vargas, quando foi colocado em debate público por meio de plataforma hospedada no site do Ministério da Cultura (culturadigital.br), e recebeu colaboração on-line direta e aberta por parte da sociedade civil brasileira (BRASIL, 2015).

${ }^{4}$ As estratégias de atuação da ARTIGO 19 incluem advocacy e campanha pela implementação de padrões internacionalmente reconhecidos nas áreas de liberdade de expressão e informação; monitoramento e pesquisa; desenvolvimento jurídico; litígio e formação (ARTIGO 19).
} 
É inegável a relevância da legislação referida ao estabelecer princípios, garantias, direitos e deveres para o uso da internet no Brasil, porém ainda há tópico que aguardam sistematização, inclusive o item relacionado à privacidade na rede. Essa temática, abarcada nos artigos $10, \S 4^{\circ}$; Art. $11, \S 3^{\circ}$ e Art. $11, \S 4^{\circ}$ da Lei $12.965 / 14$, corresponde a um dos eixos que estão sendo sistematizados, pois o "Marco Civil dispõe de forma geral sobre os direitos de privacidade dos usuários da Internet, podendo a regulamentação esclarecer essas regras" (BRASIL, 2014). A sistematização do MCI abrange, ainda, os eixos relacionados à neutralidade de rede, guarda de registros e também temas detalhamento de conceitos da lei não contemplados expressamente. De maneira semelhante ao debate público atinente à regulamentação, a sistematização, capitaneada pela Secretaria de Assuntos Legislativos (SAL) do Ministério da Justiça (MJ), está aberta à participação social de pessoas, instituições, empresas ou órgão governamental (BRASIL, 2015).

O MCI estabelece normas a fim de assegurar a titularidade do cidadão no que diz respeito aos seus dados pessoais que são tratados na internet, bem como estabelece diretrizes para a tutela da privada no tocante à guarda e ao tratamento de registros, dados pessoais ou comunicações por sites ou empresas que prestem serviços de acesso à internet, seja em relação à forma como essas informações devem ser disponibilizadas ao cidadão (art. 11, §3º ). Nesse cenário, resta evidenciada a necessidade de regulamentar os padrões de segurança para guarda de dados pessoais (Art. 10, $4^{\circ}$ ).

Nota-se que a obrigação de respeito à privacidade dos usuários é reiterada pela proibição de fornecer a terceiros os dados pessoais, os registros de conexão e de aplicação, exceto se o usuário livremente permitir. Às operadoras cabe, ainda, informar as condições a respeito da coleta, uso, tratamento, armazenamento e proteção de dados, evidenciando que existe, conforme leciona Saldanha (2015, p. 169), "uma correspondência entre o conjunto de direitos assegurados aos usuários e a previsão de responsabilidade dos provedores”.

Atendendo aos princípios da vida privada, percebe-se que a legislação confere aos provedores a responsabilidade pela guarda dos registros de conexão e de acesso a aplicações, sendo que o responsável pela guarda dos dados apenas, por ordem judicial, será obrigado a divulgá-los. Consoante ao artigo $7^{\circ}$, II e III, somente será fornecido, por meio de ordem judicial, o conteúdo das comunicações privadas. Compreende-se que a iniciativa da criação de marco regulatório decorreu do reconhecimento da influência da internet na seara da política e 
da premência de regular, no plano interno, a transposição das fronteiras através das relações virtuais.

Realizada essas considerações gerais a respeito da elaboração do Marco Civil, passa-se a traçar, sucintamente, panorama histórico do princípio da privacidade para, posteriormente, abordar a conceituação desse direito a partir do entendimento de doutrinadores constitucionalistas, tendo em vista que a legislação analisada estabelece normas para tutela da privacidade.

O nascimento do direito à privacidade, conforme leciona Rodotà (2008, p. 26), pode ser historicamente relacionado à desagregação da sociedade feudal em que o isolamento era privilégio de eleitos ou de outras pessoas as quais, por necessidade ou opção, viviam distantes da comunidade. Vieira (2007) registra, porém, que o marco doutrinário ocorreu em 1890, nos Estados Unidos, quando Samuel Dennis Warren e Louis Demitz Brandeis publicaram artigo na Harvard Law Review, intitulado Right to privacy ${ }^{5}$. Destaca-se que o direito à privacidade obteve reconhecimento na Declaração Universal dos Direitos do Homem, em 1948, e, em 1966, ganhou regulação pelo Pacto Internacional de Direitos Civis e Políticos. A previsão legal desse direito na Convenção Americana sobre Direitos Humanos aconteceu em 1969 (OEA, 1969).

Nos dias atuais, refletir a respeito da proteção do princípio da privacidade ganha relevo com a informação de que, no Brasil, 77\% dos usuários de Internet participam de redes sociais, conforme a pesquisa TIC Domicílios 2013 (PESQUISA...2014). O levantamento foi efetuado pelo Comitê Gestor da Internet (Cetic.br), do NIC.br. no período de setembro de 2013 a fevereiro de 2014.

Nessa conjuntura de consolidação do direito à privacidade e da regulação da rede, destacam-se as contribuições de Pérez-Luño e Rodotà. Oportuno ressaltar que o direito à privacidade tem a tutela garantida na Constituição da República Federativa de 1998, bem como no Marco Civil da Internet.

\footnotetext{
${ }^{5}$ Os autores analisaram alguns precedentes judiciais da Suprema Corte dos EUA referentes à propriedade, direitos autorais e difamação, concluindo que se poderia extrair das decisões o estatuto de um direito geral à privacidade. Defenderam a necessidade de reconhecimento pelas Cortes do denominado right to privacy: o direito de o indivíduo estar só com seus pensamentos, emoções e sentimentos (VIEIRA, 2007, p. 41).
} 
A Carta Magna faz distinção entre os institutos da intimidade e da privacidade, pois no art. $5^{\circ}, X$, existe uma cisão ${ }^{6}$ da intimidade de outras manifestações de privacidade.

Apesar de, na Constituição Federal, existir aparente cisão dos direitos à intimidade e à privacidade, adota-se, como já exposto na introdução, os entendimentos de Pérez Luño (2005) e Stefano Rodotà (2008). Esse reivindica a autonomia do individuo na sociedade de informacional e sugere um novo conceito de privacidade, qual seja, da definição histórica do "direito de ser deixado só" para o "direito à autodeterminação informativa". Esse conceito abarca o direito de manter o controle sobre as próprias informações; o direito de escolher aquilo que será revelado; direito ao esquecimento, em suma, o direito de determinar a maneira de construir a própria esfera particular.

Ao apresentar uma nova percepção da privacidade, Rodotà (2008) entende que esse direito tem a ver com a proteção da personalidade, não da propriedade. Assim, a ressignificação da privacidade, como direito à autodeterminação informativa, colabora para uma concepção integral da pessoa, possibilitando o livre desenvolvimento da personalidade. Desse modo, a garantia da privacidade como direito fundamental, pressupõe um ordenamento jurídico cujos regramentos sejam interpretados em consonância à pessoa humana. Nesse sentido, sublinha-se entendimento de Rodotà (2008, p. 24).

[...] cada vez mais frágil a definição de "privacidade" como o "direito a ser deixado só", que decai em prol de definições cujo centro de gravidade é representado pela possibilidade de cada um controlar o uso das informações que lhe diz respeito. Não que esse último aspecto estivesse ausente das definições tradicionais: nelas, porém, ele servia muito mais para sublinhar e exaltar o ângulo individualista, apresentando a privacidade como mero instrumento para realizar a finalidade de ser deixado só; enquanto hoje chama a atenção, sobretudo, para a possibilidade de indivíduos e grupos controlarem o exercício dos poderes baseados na disponibilização de informações, concorrendo assim para estabelecer equilíbrios sociopolíticos mais adequados.

Essa fragilidade na conceituação de privacidade como "direito a ser deixado só" resta evidenciada, especialmente, na sociedade informacional, na qual tanto as estruturas públicas como as empresas privadas realizam coleta de dados pessoais dos indivíduos.

\footnotetext{
${ }^{6}$ Mendes observa que há autores que entendem o direito à intimidade como integrante do direito à privacidade. Assim, esse abarcaria comportamentos referentes aos relacionamentos pessoais em sentido genérico, os quais o cidadão não gostariam que sejam publicizados. De outro lado, o direito à intimidade abarcaria os episódios mais íntimos atinentes às relações mais próximas (MENDES, 2008, p. 177).
} 
No que diz respeito ao "direito a ser deixado só" cabe explicitar que diz respeito à concepção liberal do direito à privacidade atrelada ao Estado mínimo, no qual prevalecia o entendimento de que bastava o Estado se abster de violar os direitos de privacidade da pessoa. Aliás, conforme explica Doneda (2006, p.8), o direito à privacidade era um direito próprio do liberalismo clássico, que poderia ser traduzido no right to be let alone. Porém, essa ideia de privacidade equivalente ao direito a ser deixado sozinho se modificou assim como se alertou a sociedade.

Ao se abordar a temática proposta, torna-se imperioso assinalar que alguns doutrinadores entendem ter a privacidade maior abrangência do que a intimidade. Assim, Moraes (2002, p. 80) afirma que "os conceitos constitucionais de intimidade e vida priva apresentam grande interligação, podendo, porém, ser diferenciados por meio da menor amplitude do primeiro que se encontra no âmbito de incidência do segundo”. Na mesma linha, Barroso (2013), ao declarar ter o entendimento que a intimidade e a privacidade formam o núcleo duro do espaço privado, permite depreender que concebe diferentes esferas da vida privada $^{7}$.

Pérez Luno (2005) assinala que os direitos fundamentais devem ser compreendidos a partir de percepções que não realizam a divisão de seus conteúdos em âmbitos apartados. Desse modo, o que se tutela é a intimidade a partir da qual os demais direitos seriam tutelados, inclusive os direitos à honra e à imagem. Compreende-se que essa concepção unitária é a mais adequada e na sociedade informacional, pois relaciona os direitos fundamentais à autonomia do titular, detentor do direito à autodeterminação informacional ${ }^{8}$.

É premente, argumenta Pérez Luño (2005, p. 65), a necessidade de transpor as concepções que serviram de base para o Estado Liberal, quando bastava a postura negativa pelo Estado para garantir a satisfação dos direitos fundamentais dos cidadãos.

\footnotetext{
${ }^{7}$ A privacidade seria o espaço no qual o homem conserva, ainda, um domínio reservado, o da sua privacidade ou vida privada. Na vida privada, se estabelecem as relações de família (e outras de afeto e amizade), protegidas do mundo exterior pelo lar, pela casa, pelo domicílio (BARROSO, 2013, p. 59).

$8 \mathrm{O}$ direito à autodeterminação concerne ao direito de o individuo determinar o seu destino, como casar-se ou não, te filhos ou não, expor em público sua própria imagem, voz e honra pessoal e demais direitos nessa mesma linha, desde que não afetem direitos de terceiros, nem a lei moral, nem a ordem constitucional (SARMENTO, 2004, p. 204).
} 
O posicionamento ativo do Estado torna-se ainda mais essencial ao compreender os direitos fundamentais na dimensão social. Assim, resta evidenciada o imperativo do reconhecimento do controle de fluxo informacional pelo próprio indivíduo.

Insta enfatizar a distinção entre intimidade e privacidade realizada pela doutrina alemã, a qual distingue a privacidade em três círculos concêntricos. Nesse sentido, destacase a explicação de Vieira a respeito da teoria das esferas (2007, p. 37).

O primeiro círculo e de maior amplitude representa a esfera privada, excluindo-se do conhecimento de terceiros aspectos específicos da vida da pessoa. $\mathrm{O}$ segundo compreende os valores atinentes ao âmbito da intimidade ou esfera confidencial, cujo acesso é mais restrito, somente permitido àqueles indivíduos com os quais a relação pessoal se desenvolve de forma mais intensa. O terceiro e mais fechado dos círculos abrange a reserva, o sigilo, o segredo, as mais profundas manifestações espirituais da pessoa, caracterizadoras da vida íntima stricto sensu.

Percebe-se que essa teoria, adotada pelo Tribunal Federal Constitucional Alemão ${ }^{9}$ no caso da Lei do Microcenso, realiza diferenciação entre intimidade, vida privada e segredo, apesar de ser questionável a possibilidade de delimitar os limites que balizam as três esferas. A par da teoria das esferas houve a formulação da teoria do mosaico, em que a partir de coletânea de dados é possível traçar o perfil do cidadão, por Fulgêncio Conessa ${ }^{10 .}$ Aliás, Canotilho (2003) conceitua direito à privacidade como direito de personalidade. O constitucionalista português faz distinção ${ }^{11}$ entre direitos de personalidade e direitos fundamentais 12 .

\footnotetext{
${ }^{9}$ Em 16 de julho de 1960, o Tribunal Alemão afirmou que o terceiro e mais fechado dos círculos não pode ser violado pelo Estado nem mesmo por lei, por ser tal âmbito um recinto inatingível da vida privada, que não pode ser submetido a qualquer ação do poder público. [...] De outro lado, as informações solicitadas pelos órgãos públicos, que exorbitem essa esfera e que não violem a dignidade ou a autodeterminação do individuo, devem ser prestadas ao Estado para pesquisas estatísticas, por exemplo. No caso em exame, o Tribunal considerou que a Lei de Microcenso não viola a esfera do segredo confirmando a constitucionalidade do ato normativo (VIEIRA, 2007, p. 39).

${ }^{10}$ Dados pessoais assemelham-se a pequeninas pedras que formam um mosaico, ou seja, vistas por si sós nada representam, mas, uma vez unidas, formam um conjunto pleno de significado que, nesse caso, compõem a personalidade do indivíduo (BESSA, 2003, p. 114).

${ }^{11} \mathrm{O}$ autor reconhece que, em razão da interdependência entre o estatuto positivo e o estatuto negativo do cidadão, e em face da concepção de um direito geral de personalidade como direito à pessoa ser e à pessoa devir, cada vez mais os direitos fundamentais tendem a ser direitos de personalidade e vice-versa (CANOTILHO, 2003, p. 396).

${ }^{12}$ Direitos fundamentais são os direitos do homem, jurídico-institucionalmente garantidos e limitados espaçotemporalmente (CANOTILHO, 2003, p. 392).
} 
Segundo o constitucionalista português, os direitos de personalidade abrangem os direitos de estado (direito de cidadania), os direitos distintivos da personalidade (direito à identidade pessoal, direito à informática) e os direitos sobre a própria vida.

Segundo a teoria do mosaico, é irrelevante o fato de a informação do indivíduo pertencer à esfera da intimidade, vida privada do segredo, pois interessa, sobretudo, é a utilização que se fará com tal dado informacional. Assim, há dados que possuem aparência de inofensivos à violação, porém, quando colacionados com outros dados, apresentam risco à violação da privacidade do cidadão. Destaca-se que a teoria do mosaico colabora para o entendimento da problemática relacionada à coleta $\mathrm{e}$ ao armazenamento de dados pessoais tanto por entes públicos quanto por privados, em especial na sociedade informacional na qual é possível realizar, em instantes, a interligação de dados e delinear o perfil de indivíduos.

Realizada essa abordagem conceitual a partir da doutrina, compreende-se o direito à privacidade, consagrado no âmbito internacional já no século XVI, como uma garantia essencial ao pleno desenvolvimento do indivíduo. Passa-se, na próxima seção, a análise crítica das decisões dos Tribunais Superiores fundamentadas no Marco Civil da Internet.

\section{ANÁliSE DE DECISÕES DOS TRIBUNAIS EM COTEJO AO EMPREGO DO MARCO CIVIL DA INTERNET}

Nessa seção realiza-se a análise da utilização de parâmetros estabelecidos no Marco Civil da Internet nas fundamentações das decisões proferidas pelos Tribunais Superiores do país, especialmente nas demandas envolvendo tutela do princípio da privacidade dos usuários da rede, tendo em vista a obrigatoriedade de os provedores guardarem os registros de conexão e de acesso. Em pesquisa realizada nos sites dos Tribunais Superiores percebe-se a escassez na aplicação do MCI nas fundamentações das decisões judiciais apesar de o marco regulatório ter completado um ano de vigência.

Antes de se passar à verificação dos portais, destaca-se que assuntos relacionados à privacidade na rede permearam as discussões do MCI e balizaram a construção do diploma legal. Nesse sentido, ressalta-se o art. $7^{\circ}$ que estabelece os direitos dos usuários no que diz respeito à privacidade. Destacam-se os artigos 13 e 15 atinentes à retenção de logs de 
conexão e aplicações pelos provedores de serviço. Desse modo, os registros de conexão e de acesso a aplicações de internet devem ser mantidos sob sigilo, em ambiente controlado e de segurança, cabendo ao administrador a guarda de dados dos logs de conexão. Nas diretrizes do Marco Civil, definiu que os provedores de aplicativos são obrigados a armazenar, por seis meses, os registros de acesso de seus usuários e os registros, para fins de investigação, somente serão acessados mediante autorização judicial. Feita essa sinopse, realiza-se a verificação dos sites dos Tribunais Regionais Federais. No site do Tribunal Regional Federal da $1^{\text {a }}$ Região ${ }^{13}$, a pesquisa de jurisprudência localizou dezessete acórdãos, porém ao acessar o resultado da busca o site apresentava falhas ${ }^{14}$. O mesmo procedimento de pesquisa realizou-se nos Tribunal Federais da $3^{\mathrm{a} 15}, 4^{\mathrm{a} 16}$ e $5^{\mathrm{a} 17}$ Região e, em todos os casos, não foram localizados acórdãos calcados no Marco Civil da Internet, ou seja, as decisões envolvendo questões de privacidade na Internet não mencionavam o MCI.

Já na jurisprudência do Tribunal Regional Federal da $2^{\mathrm{a}}$ Região ${ }^{18}$ localizou-se apenas uma decisão em que se fez o uso da Lei 12.965/14 no teor da fundamentação (BRASIL, 2014a). O episódio diz respeito ao agravo impetrado pelo Ministério Público Federal a fim de obter liminar, obrigando o Youtube a retirar do ar vídeos com conteúdos ofensivos às religiões afro-brasileiras. O relator do processo determinou, baseado no art. 10 do MCI e para preservação da intimidade dos envolvidos, que os dados relativos à data, à hora, ao local e ao número de identificação do IP dos computadores que colocaram os vídeos fossem armazenados em ambiente seguro.

Percebe-se que, nesta decisão do TRF da $2^{\mathrm{a}}$ região, mesmo timidamente, a menção à tutela do direito da privacidade, abordado, nesse acórdão, como intimidade.

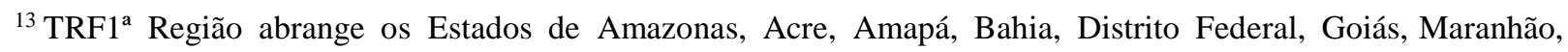
Mato Grosso, Minas Gerais, Pará, Piauí, Rondônia, Roraima e Tocantins.

${ }^{14}$ Por inúmeras vezes e em dias diferentes, o site apresentava a mensagem: "Sua sessão expirou, por favor, feche esta janela e faça uma nova consulta!"

15 O TRF $3^{\text {a }}$ Região abrange os Estados de Minas Gerais e de São Paulo.

${ }^{16}$ Os Estados do Rio Grande do Sul, Santa Catarina e Paraná compõem o TRF da $4^{\text {a }}$ Região.

${ }^{17}$ Alagoas, Ceará, Paraíba, Pernambuco, Rio Grande do Norte e Sergipe são os Estados abarcados pelo TRF da $5^{\text {a }}$ Região.

${ }^{18}$ TRF 2 ${ }^{\mathrm{a}}$ Região é composto pelos Estados do Rio de Janeiro e Espírito Santo.
} 
Apesar de o desembargador não mencionar o significado de intimidade/privacidade, destacou, textualmente, que determinou o armazenamento dos dados "diante da imperiosa preservação da intimidade dos envolvidos, nos termos do artigo 10 da Lei 12.965, de 23 de abril de 2014". No acórdão, o Tribunal afirma que a manutenção dos vídeos, por serem fomentadores do discurso de ódio, provocaria danos constantes à sociedade e, em razão disso, entendeu como cabível a retirada dessas mídias da internet, determinando o armazenamento das informações. Essa determinação judicial tem como base o art.10 do Marco Civil da Internet, porém não refere a respeito dos procedimentos para garantir a segurança da guarda das informações.

Concorda-se com a função de existir discurso de ódio nos vídeos publicados, pois os vídeos possuíam conteúdo discriminatório e eram dotados da característica da externalidade, componentes caracterizadores do referido discurso. Nesse sentido, destaca-se o entendimento de Silva et al. (2011) a respeito de discurso de ódio.

É uma manifestação segregacionista, baseada na dicotomia superior (emissor) e inferior (atingido) e, como manifestação que é, passa a existir quando é dada a conhecer por outrem que não o próprio autor. A fim de formar um conceito satisfatório, devem ser aprofundados esses dois aspectos, começando pela externalidade. A existência do discurso de ódio, assim toda expressão discursiva, exige a transposição de ideias do plano mental (abstrato) para o plano fático (concreto). Discurso não externado é pensamento, emoção, o ódio sem o discurso; e não causa dano algum a quem porventura possa ser seu alvo, já que a ideia permanece na mente de seu autor.

O teor do acórdão possibilita entender que aconteceu manifestação segregacionista, que ganhou contornos externos com a publicação dos vídeos na internet. Feita essa observação a respeito do conteúdo objeto do acórdão, retorna-se à analise da decisão do TRF.

Em relação à aplicação de punições para o infrator, registra-se que o acórdão menciona apenas aplicação de multa em caso de descumprimento da ordem judicial, apesar de o Marco Civil da Internet, em seu art. 12, estipular a possibilidade de concessão de sanções cíveis, criminais ou administrativas, aplicadas isoladas ou cumulativamente. Essa postura, diga-se reducionista de apropriação de dispositivos do MCI, talvez ocorra em decorrência de a própria litigante, especificamente o Ministério Público Federal, não utilizar a Lei 12.965/14 na fundamentação de seu pedido. 
Percebe-se que a adoção do Marco Civil da Internet nas fundamentações dos Tribunais acontece de forma lenta, mas, decisão recente do Plenário do Superior Tribunal Militar (STM), tendo por fulcro alguns dispositivos do MCI, pode representar o início da consolidação do regramento infraconstitucional. Em maio de 2015, o STM determinou, de maneira unânime, que empresa Facebook (proprietária do aplicativo Whatsapp) fornecesse o registro de uso de conta vinculada a um soldado do Exército (BRASIL, 2015a).

Neste episódio, o Ministério Público Militar solicitou a quebra do sigilo do Whatsapp para averiguar a hipótese de o soldado estar mandando mensagens enquanto dirigia. $\mathrm{Na}$ primeira instância, a Justiça Militar da União, em Bagé, indeferiu o pedido do MPM no que dizia respeito aos dados do Whatsapp, argumentando que a quebra do sigilo infligiria direitos e garantias fundamentais previstos na Constituição Federal. Já no Superior Tribunal Militar, em decisão inédita, houve provimento parcial do pedido do Ministério Público, determinando à Facebook o fornecimento do registro do fluxo das mensagens enviadas, mas sem transcrição de conteúdo.

Destaca-se que ao relator o caso, o ministro Marcus Vinicius de Oliveira enfatizou que o deferimento da invasão da privacidade deve observar a necessidade da medida. Nesse sentido, ressalta-se trecho do relator (BRASIL, 2015).

[...] este juízo entende que, diferentemente da quebra do sigilo telefônico, a quebra do sigilo de mensagens enviadas e recebidas através do aplicativo "Whatsapp" não deve ser deferida, por não encontrar guarida nos casos da lei 12.965 , de 23 de abril de 2014, que regula a medida. [...] a quebra de sigilo pretendido é medida de investigação que excepciona a inviolabilidade da intimidade e somente deve ser adotada quando esgotados todos os meios ordinários para o esclarecimento do pretenso ilícito penal.

Percebe-se que o Ministro Relator utilizou o respaldo legal do Marco Civil na fundamentação da concessão do mandado de segurança em conjunto ao direito da inviolabilidade da intimidade constante no art. $5^{\circ}$ da Constituição Federal de 1988. Assim, há uma coerência na aplicação do dispositivo infraconstitucional em consonância aos parâmetros do Estado Democrático e de Direito.

Restou evidenciada a preocupação em defender a pessoa nas dimensões da privacidade e da intimidade e, consequentemente, garantir a mantença dos valores fundamentais dos sistemas democráticos. Entende-se que, por se tratar de direito fundamental, as barreiras ao 
direito à privacidade são legitimas quando há possível colisão com outros direitos da mesma categoria.

\section{CONSIDERAÇÕES FINAIS}

Na sociedade informacional, a interconexão de mecanismos possibilita traçar perfis, monitorar comportamentos e processar informações dos indivíduos. Nesse cenário de rápidos avanços tecnológicos em que o cidadão torna-se a parte vulnerável na rede de informações, resta comprovada a necessidade de iniciativas estatais para tutelar o direito à privacidade não apenas em face do Estado, mas também no tocante à coletividade. É inegável avanço legislativo e político o fato de Estado ter elaborado, de forma colaborativa coma sociedade civil, a Lei 12.965, de 23 de abril de 2014. Assim, ao criar marco regulatório civil da Internet, o Poder Público estabeleceu aparato legal de implementar medida necessária à concretização do direito à privacidade. Há, ainda, a necessidade de regulamentação de aspectos da privacidade na rede, mas pode-se afirmar que, o ente estatal realizou atuação positiva do Estado para assegurar a não interferência de terceiros na vida privada do cidadão.

Reitera-se que o direito à privacidade ressignificação da privacidade, como direito à autodeterminação informativa, colabora para uma concepção integral da pessoa, possibilitando o livre desenvolvimento da personalidade. Desse modo, a garantia da privacidade como direito fundamental, pressupõe um ordenamento jurídico cujos regramentos sejam interpretados em consonância à pessoa humana. Assim, enfatizou-se a fragilidade da definição de privacidade como o "direito a ser deixado só", pois, no mundo interconectado, é inviável a possibilidade de cada individuo controlar e monitorar a utilização de informações que lhe dizem respeito.

A partir da reflexão e análise realizadas ao longo do artigo, concluiu-se que os Tribunais Federais do Brasil ainda não utilizam o arcabouço legal do Marco Civil da Internet em suas fundamentações, apesar de a Lei estar em vigência desde abril de 2004. Percebeuse, nas reduzidas decisões fundamentadas no MCI, que o Poder Judiciário tem realizado análise ainda não criteriosa da legislação em cotejo com o direito à privacidade constante na Constituição Federal de 1988. 


\section{REFERÊNCIAS}

ARTIGO 19. BRASIL: Marco Civil da Internet. Disponível em: <http://artigo19.org/liberdadedigital/files/2014/01/Brazil-Marco-Civil-port-final.pdf>. Acesso em 20 jun. 2015.

BARROSO, Luiz Roberto. A dignidade da pessoa humana no direito constitucional contemporâneo: a construção de um conceito jurídico à luz da jurisprudência mundial. Traduzido por Humberto Laport de Mello. Belo Horizonte: Fórum, 2013.

BESSA, Leonardo Roscoe. O consumidor e os limites dos bancos de dados de proteção ao crédito. São Paulo. Revista dos Tribunais, 2003.

BRASIL. Tribunal Regional Federal da $2^{a}$ Região. Acórdão de decisão que determina armazenamento de dados requeridos a fim de assegurar a eficácia da tutela jurisdicional. Agravo de instrumento n²01400001010430. Ministério Público Federal do Rio de Janeiro e Youtube. Relator: Desembargador Reis Friede. 28 de agosto de 2014. Disponível em: $\quad<$ http://jurisprudencia.trf2.jus.br/v1/search?q=marco+civil+da+internet\&client=jurisp rudencia\&output=xml_no_dtd\&proxystylesheet=jurisprudencia\&lr=lang_pt\&ulang=p ～tBR\&entqrm $=0 \& w c=200 \& w c \_m c=1 \& o e=U T F-8 \& i e=U T F-$

$8 \& u d=1 \&$ exclude_apps $=1 \&$ sort $=$ date $\% 3 \mathrm{AD} \% 3 \mathrm{AS} \% 3 \mathrm{Ad} 1 \&$ entqr $=3 \&$ site $=$ ementas $\&$ filter $=0$ $\&$ getfields $=* \&$ partialfields $=\&$ requiredfields $=\&$ as_q $=>$.Acesso em: 12 jun. 2015.

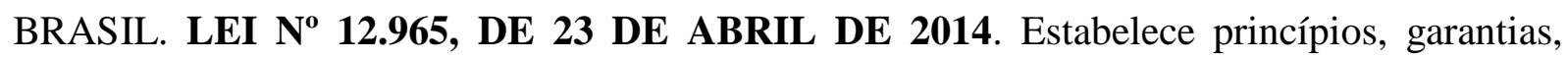
direitos e deveres para o uso da Internet no Brasil. Disponível em: < <http://www.planalto.gov.br/ccivil_03/_ato2011-2014/2014/lei/112965.htm>. Acesso em: 5 jun. 2015.

BRASIL. Superior Tribunal Militar. Decisão do magistrado a quo que indeferiu o pedido de quebra do sigilo do fluxo de mensagens trocadas por meio do aplicativo "Whataspp" dos aparelhos celulares do indiciado. Mandado de segurança $\mathrm{n}^{\circ}$ 000004152.2015.7.00.0000. Ministério Público Militar e Whatsapp. Relator: Desembargador Marcus Vinicius Oliveira dos Santos. Disponível em: <http://www2.stm.jus.br/cgi-bin/nphbrs?s1=0000041-

52.2015.7.00.0000\& $\mathrm{l}=20 \& \mathrm{~d}=\mathrm{JURI} \& \mathrm{p}=1 \& \mathrm{u}=\mathrm{j} \& \mathrm{r}=1 \& \mathrm{f}=\mathrm{G} \& \operatorname{sect} 1=$ NOVAJURI $>$. Acesso em: 12 jun. 2015a. 
BRASIL. Portal Brasil. Disponível em: <http://www.brasil.gov.br/cidadania-ejustica/2015/01/perguntas-e-respostas-mci.doc>. Acesso em: 13 jun. 2015.

. Ministério da Justiça. Disponível em:

<http://participacao.mj.gov.br/marcocivil/sistematizacao/>. Acesso em: 16 jun. 2015.

CANOtilho, Joaquim José Gomes. Direito Constitucional e Teoria da Constituição. Coimbra. Almedina, 2003.

CASTELLS, Manuel. A sociedade em rede. 8. ed. Traduzido por Roneide Venâncio Majer. São Paulo: Paz e Terra, 2005.

DONEDA, Danilo. Da privacidade à proteção de dados pessoais. Rio de Janeiro: Renovar, 2006.

MENDES, Gilmar Ferreira. Curso de direito constitucional. 2. ed. São Paulo: Saraiva, 2008, p. 377.

MORAIS, Alexandre de. Direito Constitucional. 12a ed. São Paulo: Atlas, 2002, p. 80. OEA. Pacto de San José da Costa Rica. Convenção Americana sobre Direitos Humanos. 22 de novembro $\quad 1969 . \quad$ de $\quad$ Disponível em <http://www.mj.gov.br/sedh/ct/legisintern/conv_americana_dir_humanos. htm>. Acesso em: 12 jun. 2015.

PESQUISA sobre o uso das tecnologias da informação e comunicação no setor público brasileiro [livro eletrônico]: TIC Governo Eletrônico 2013. São Paulo: Comitê Gestor da Internet no 2014.2 Disponível em: http://cetic.br/media/docs/publicacoes/2/TIC_eGOV_2013_LIVRO_ELETRONIC O.pdf. Acesso em: 5 jun. 2015.

PESQUISA sobre o uso das tecnologias da informação e comunicação no Brasil: TIC Domicílios 2013. São Paulo: Comitê Gestor da Internet no Brasil, 2014. Disponível em: <http://www.cetic.br/media/analises/tic-domicilios-2013.pdf>. Acesso em: 16 jun. 2015.

PÉREZ LUÑO, Antonio - Henrique. Derechos humanos, Estado de Derecho y Constitución. 9. ed. Madri: Editorial Tecnos, 2005. 
RODOTÀ, Stefano. A vida na sociedade da vigilância: a privacidade hoje. Traduzido por Daniel Doneda e Luciana Cabral Doneda. Rio de Janeiro: Renovar, 2008.

SALDANHA, Jânia. Marco Civil da Internet: um quadro de princípios, responsabilidades e de protagonismo do Poder Judiciário. In: Silva, Rosane Leal da. (Org.).O Poder Judiciário na Sociedade em Rede: jurisdição, informação e transparência. Curitiba, Multideia, 2015.

SILVA, Rosane Leal da et al . Discursos de ódio em redes sociais: jurisprudência brasileira. Rev. direito GV, São Paulo, v. 7, n. 2, p. 445-468, Dec. 2011. Available from $<$ http://www.scielo.br/scielo.php?script=sci_arttext\&pid=S1808-

$24322011000200004 \& \operatorname{lng}=$ en\&nrm=iso>. Acesso em: 15 jun. 2015.

SARMENTO, Daniel. Direitos Fundamentais e relações privadas. Rio de Janeiro: Lumen Juris, 2004, p. 204.

VIEIRA, Tatiana Malta. $\mathbf{O}$ direito à privacidade na sociedade da informação: efetividade desse direito fundamental diante dos avanços da tecnologia da informação. Porto Alegre: Sergio Antonio Fabris Ed, 2007. 